\title{
Spinal Neurocytoma: A Case Report and Review of Literature
}

\author{
Khalil Guedira $^{1} \quad$ Nidhal Matar $^{1} \quad$ Maher Ben Salem $^{1} \quad$ Ines Chelly ${ }^{1}$ Ihsen Zemmel ${ }^{1}$ \\ ${ }^{1}$ Department of Neurosurgery, University El Manar Tunis, Tunis, Tunisia \\ Address for correspondence Nidhal Matar, MD, Department of \\ Indian J Neurosurg 2017;6:228-231. \\ Neurosurgery, University El Manar Tunis, Rue jebel Lakhdar la Rabta, \\ 1007 Tunis, Tunisia (e-mail: matarnidhal2007@yahoo.fr).
}
Abstract
Extraventricular locations of neurocytoma are extremely rare, especially in the spinal
Keywords
- neurocytoma
- extraventricular cord, which has been reported in only sporadic cases. In this article, we report a new pediatric case of a spinal neurocytoma in a 12-year-old girl and briefly review the
- spine relevant literature.

\section{Introduction}

Since 1982, central neurocytoma has been recognized as a distinct class of central nervous system (CNS) tumors. It has been defined as a typically benign supratentorial mass located within the lateral or the third ventricle. ${ }^{1}$ Extraventricular locations are extremely rare, especially in the spinal cord, which has been reported in only sporadic cases. In this paper, we report a new pediatric case of a spinal neurocytoma $(\mathrm{SN})$ and briefly review the relevant literature.

\section{Case Description}

A 12-year-old girl presented with a history of 6 months slowly progressive lower limb weakness, associated to sphincter dysfunction starting 1 month ago, and requiring an indwelling urinary catheter. She also complained of chronic cervical and lumbar pain. The neurologic examination showed a flaccid paraplegia, a lower limb areflexia with a right Babinski's sign, and an L1 sensory level. The magnetic resonance imaging (MRI) showed an intradural intramedullary tumor at T10 to T12 level with an extensive syringohydromyelia (-Fig. 1). The tumor was iso-intense on T1-weighted images and slightly hyperintense on T2weighted images. After gadolinium administration, there is a homogenous enhancement. The diagnosis of ependymoma was initially suspected. A D10 to D12 laminectomy was performed, followed by gross total resection of an ovalshaped intramedullary tumor. It was a grayish hemorrhagic and friable lesion surrounded by a thin white capsule.
Postoperatively, the patient developed a transient constipation and no motor improvement was noticed till her discharge. In pathologic examination, hematoxylin and eosin (H\&E)-stained sections showed a monomorphic proliferation of small round cells with round and hyperchromatic nuclei. Tumor cells were clustered in honeycomb structures like in oligodendroglioma. In hypocellular areas, cells were surrounded by a fibrillary matrix. Ependymomalike areas and some ganglion cells were noticed. No mitoses were found, and necrosis and vascular proliferation were absent as well. Immunohistochemistry showed a diffuse and intense expression of synaptophysin by tumor cells. Glial fibrillary acidic protein (GFAP) as well as isocitrate dehydrogenase 1 (IDH1) was negative. Nuclear labeling with P53 was focal, and the proliferation index with the Ki67 was $2 \%$. We concluded to a grade II extraventricular neurocytoma (EVN) (-Fig. 2). No adjuvant treatment was undertaken. At 5 months after surgery, the patient is able to walk with two crutches and sphincter disorders disappeared (-Fig. 3).

\section{Discussion}

Central neurocytomas are benign tumors comprising 0.1 to $0.4 \%$ of all CNS neoplasm. It usually arises from the lateral ventricle. In 2007, the World Health Organization (WHO) recognized "extraventricular neurocytoma (EVN)" as a separate entity and denoted such arising in different locations, including the cerebrum, pineal, hypothalamus, thalamus, corpus callosum, cerebellum, pons, spinal cord, received

September 19, 2016

accepted

January 23, 2017

published online

May 25, 2017
DOI https://doi.org/

10.1055/s-0037-1601366.

ISSN 2277-954X.
(C) 2017 Neurological Surgeons' Society

of India
License terms

(®) $\Theta \circledast$ 


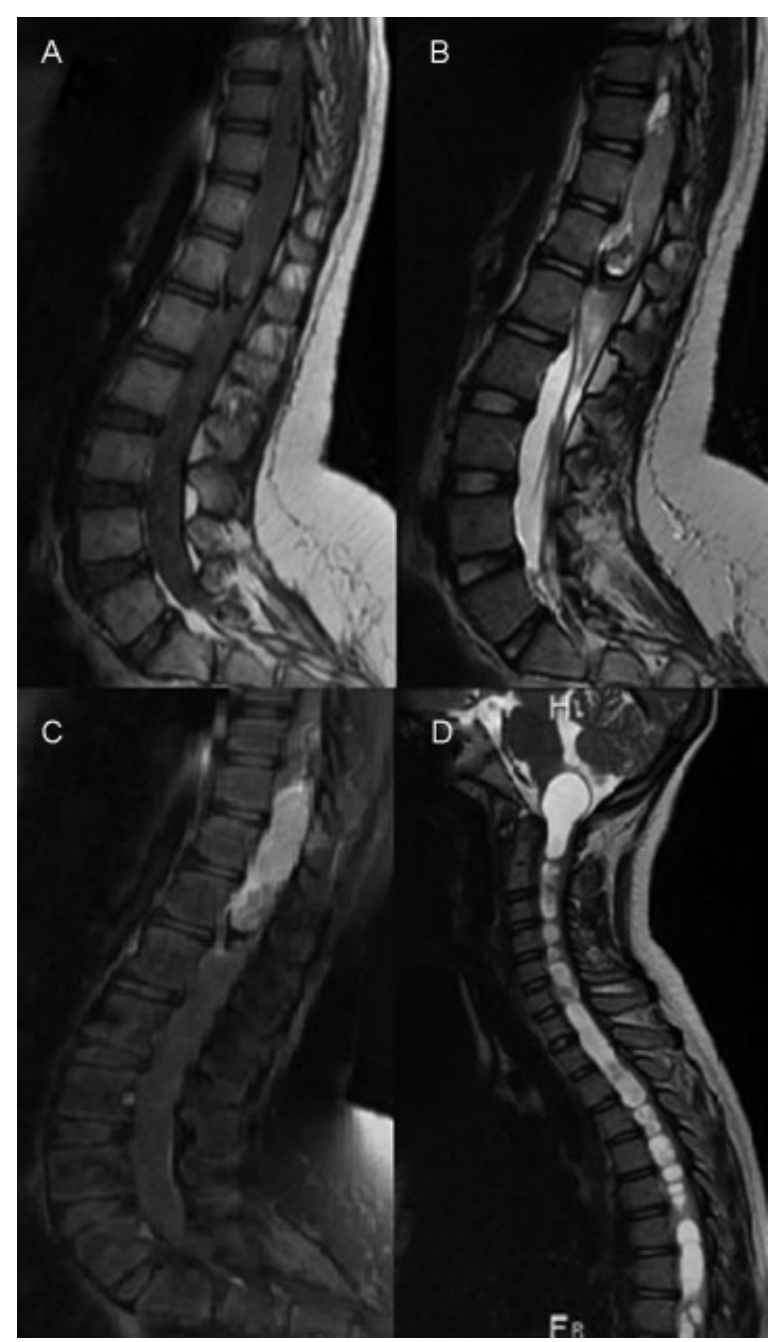

Fig. 1 Sagittal sections of spinal MRI. The tumor is iso-intense on T1 image (A), moderately hyperintense on $\mathrm{T} 2$ image (B), with a homogenous enhancement after gadolinium injection (C). There is an extensive syringohydromyelia up to bulb (D).

cauda equina, or retina. ${ }^{2-5}$ However, spinal cord localization is extremely rare and reported as sporadic cases. The reviews of international literature revealed only 22 cases (-Table 1).

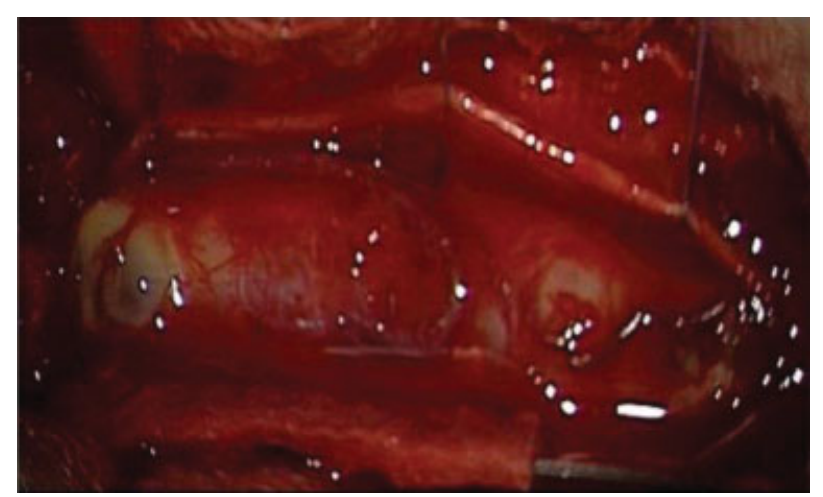

Fig. 2 Intraoperative photography of the intradural intramedullary encapsulated tumor.
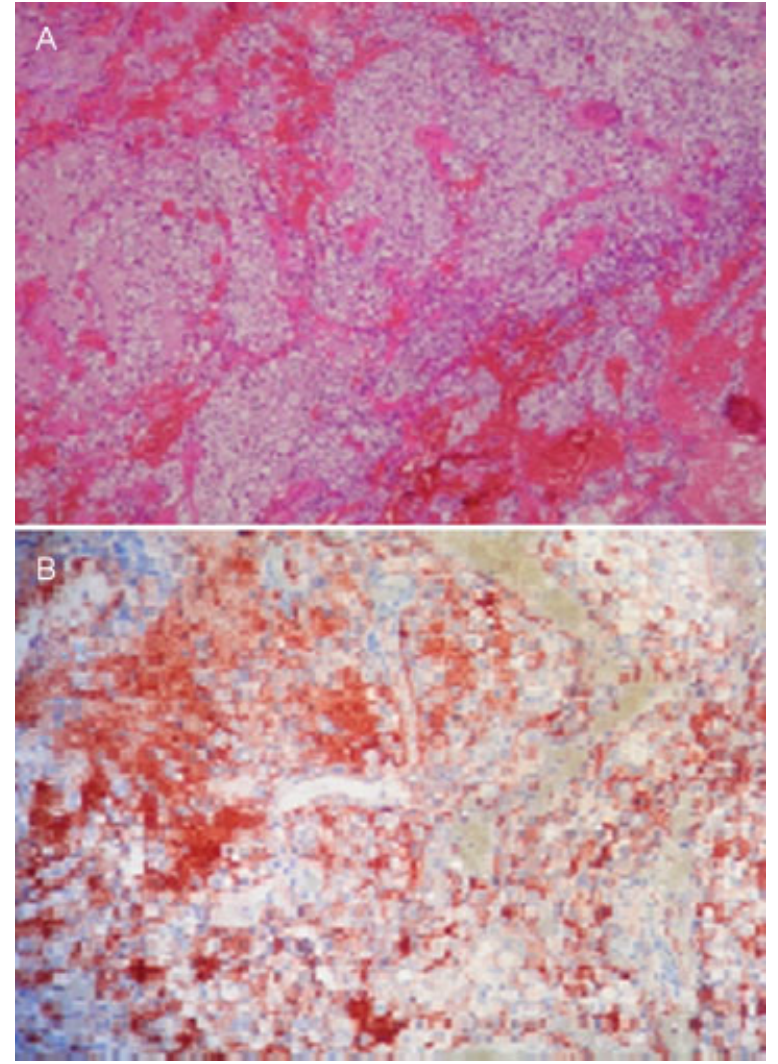

Fig. $3 \mathrm{H} \& \mathrm{E} \times 10$ : monomorphic round cell proliferation with an oligodendroglioma-like organization in honeycomb structures. Tumor background is fibrillary with some acellular ependymoma-like areas (A). Immunohistochemical staining shows a strong and diffuse positivity for synaptophysin (B).

SN usually affects young adults; when our example is included, the median age is 33 years varying from 6 to 68 years, with only eight pediatric cases. There is a slight male predominance (sex ratio: 1.87:1).

As a benign tumor, neurocytomas tend to grow slowly; therefore, patients tend to experience progressive symptoms and evolution. They are more likely to present with sensory and motor deficits of the upper or lower extremities. The clinical presentation depends on the tumor location and consists commonly of a myelopathy: weakness, numbness, and paresthesia. Bowel and bladder sphincter dysfunction may occur with involvement of the conus medullaris. ${ }^{6,7}$ Disorientation has also been described in a patient whose T1-T5 tumor disrupted cerebrospinal fluid flow, resulting in MRI-confirmed hydrocephalus. ${ }^{6}$ Moreover, intracranial hypertension symptoms occurred in one case with a tumor extending from the bulb to $\mathrm{C} 7 .{ }^{8}$

The MRI appearance does not differ from that of central neurocytomas. It presents typically as a unique, solid, and well-circumscribed intradural intramedullary mass. It has usually an iso-intense or mildly hyperintense on T1- and T2-weighted images (except in the example reported by Singh et al, which was hypointense on T1). ${ }^{9}$ Lesions have been shown to enhance hetero- or homogeneously with gadolinium administration. SNs often contain calcification 


\begin{tabular}{|c|c|c|c|c|c|c|c|c|c|c|c|c|c|c|c|c|c|c|c|}
\hline 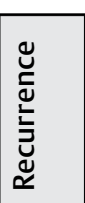 & z & $\stackrel{\tilde{a}}{>} \stackrel{0}{z}$ & z & z & z & z & z & $\S$ & $\stackrel{\tilde{y}}{\nu}$ & z & $\Sigma$ & z & $\stackrel{\tilde{u}}{z} \stackrel{0}{z} \stackrel{0}{z}$ & 2 & 인 & 울 & $\S$ & z 2 & z \\
\hline 容 & 음 & $\mid \begin{array}{l}\stackrel{\circ}{E} \\
\stackrel{\mathrm{m}}{\mathrm{m}} \text { in }\end{array}$ & $\begin{array}{l}\stackrel{\circ}{E} \\
\stackrel{m}{m}\end{array}$ & $\mid \stackrel{\circ}{E}$ & 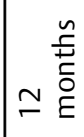 & $\begin{array}{l}\stackrel{̊}{E} \\
m \\
m\end{array}$ & $\begin{array}{l}\stackrel{O}{E} \\
\stackrel{\sim}{J}\end{array}$ & $\Sigma$ & 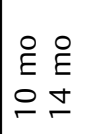 & $\mid \begin{array}{l}O \\
E \\
m\end{array}$ & $\Sigma$ & $\begin{array}{l}\stackrel{\circ}{E} \\
\stackrel{\sim}{\simeq}\end{array}$ & 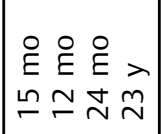 & $\begin{array}{l}\circ \\
\stackrel{\circ}{E} \\
\varrho \\
-\end{array}$ & \begin{tabular}{|l|}
$\circ$ \\
$E$ \\
6
\end{tabular} & $\mid \begin{array}{ll}O & \circ \\
& \mathcal{E} \\
6 & 6\end{array}$ & $\S$ & 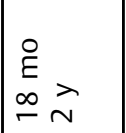 & 2 \\
\hline 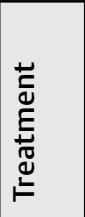 & 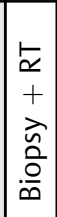 & 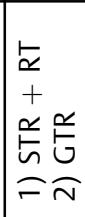 & 壴 & 鲁 & 兰 & 䋦 & 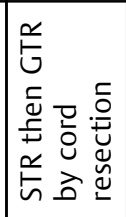 & $\S$ & 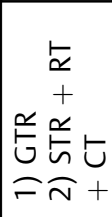 & $\frac{\underline{c}}{\omega}$ & $\stackrel{\underline{a}}{n}$ & 兴 & 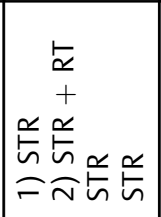 & $\begin{array}{l}\frac{\mathfrak{\alpha}}{\alpha} \\
+ \\
\underline{a} \\
\underline{\omega}\end{array}$ & 喜 & 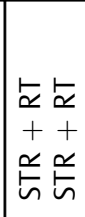 & $\underline{\underline{n}}$ & 总受 & 亳 \\
\hline 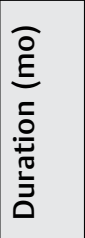 & $\stackrel{\infty}{-}$ & 6 & $\stackrel{\infty}{+}$ & $\sim$ & $\sim$ & $\S$ & $m$ & $m$ & $m$ & $\stackrel{\Xi}{\sim}$ & in & $\S$ & $m \simeq \sim$ & 6 & $\simeq$ & $\S \Sigma$ & $\S$ & $8 a$ & 6 \\
\hline 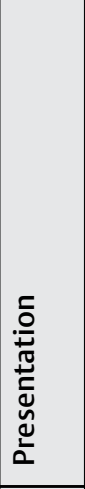 & 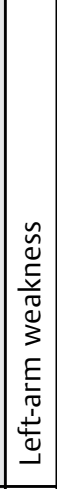 & 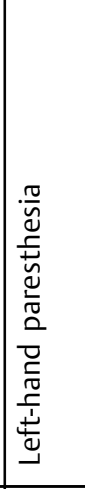 & 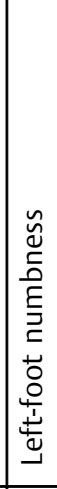 & 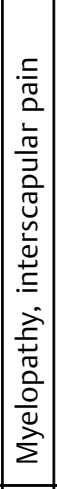 & 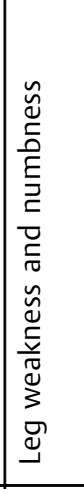 & 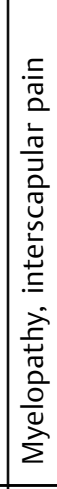 & 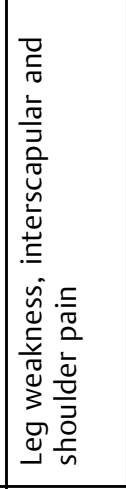 & 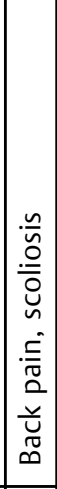 & 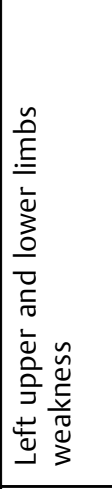 & 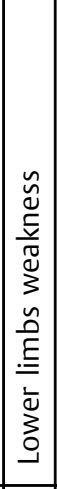 & 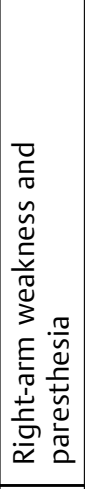 & 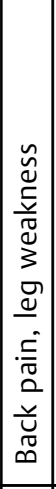 & 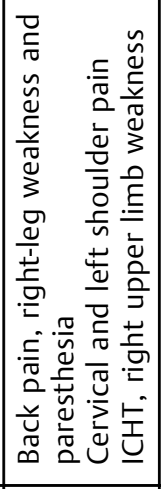 & 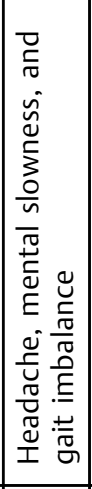 & 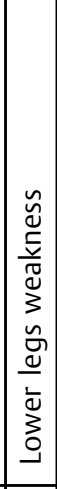 & $\S \Sigma$ & 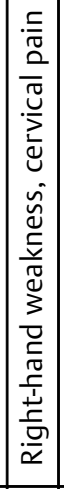 & 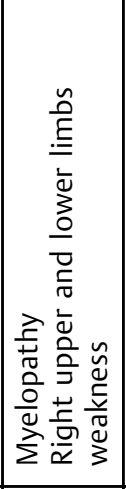 & 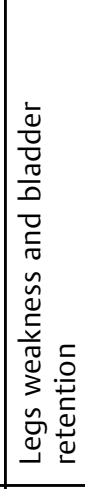 \\
\hline$\frac{n}{\stackrel{\Xi}{J}}$ & $\begin{array}{l}0 \\
1 \\
1 \\
\tilde{U}\end{array}$ & $\begin{array}{l}J \\
1 \\
0 \\
0\end{array}$ & $\begin{array}{l}E \\
F \\
F\end{array}$ & $\begin{array}{c}E \\
\\
\end{array}$ & $\begin{array}{l}\overline{1} \\
\stackrel{1}{\sim} \\
\Sigma\end{array}$ & $\begin{array}{l}F \\
1 \\
\stackrel{U}{2}\end{array}$ & 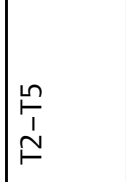 & $\begin{array}{l}E \\
F \\
1 \\
\qquad\end{array}$ & $\begin{array}{l}F \\
1 \\
\end{array}$ & $\begin{array}{l}\infty \\
\stackrel{\infty}{1} \\
\stackrel{1}{F}\end{array}$ & $\begin{array}{l}0 \\
1 \\
1 \\
0\end{array}$ & $\begin{array}{c}E \\
F \\
\vdots \\
0 \\
F\end{array}$ & 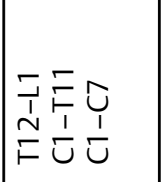 & $\begin{array}{l}\frac{n}{r} \\
\frac{1}{F}\end{array}$ & $\begin{array}{l}\stackrel{n}{\rho} \\
1 \\
\stackrel{m}{r}\end{array}$ & $\Sigma \Sigma$ & 訔 & 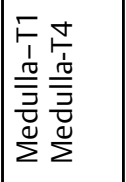 & $\mid \begin{array}{l}\mathfrak{N} \\
F \\
1 \\
0 \\
F\end{array}$ \\
\hline$\stackrel{x}{\varpi}$ & $\Sigma$ & $\Sigma$ & $\Sigma$ & $\Sigma$ & L & $\Sigma$ & $\Sigma$ & $\Sigma$ & $\Sigma$ & $\Sigma$ & \llcorner & $\Sigma$ & $4 \Sigma \Sigma$ & 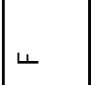 & \llcorner & $\Sigma \Sigma$ & 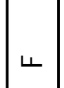 & $4 \Sigma$ & 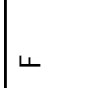 \\
\hline 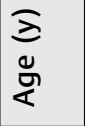 & $\infty$ & g & 6 & $\simeq$ & fo & $\simeq$ & in & $m$ & $\stackrel{ \pm}{\sim}$ & $\infty$ & g & in & 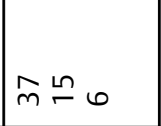 & 華 & ถึ & $\stackrel{\varphi}{\sim} \stackrel{n}{\sim}$ & $\stackrel{2}{\sim}$ & $\stackrel{\infty}{+} \stackrel{0}{N}$ & $\simeq$ \\
\hline 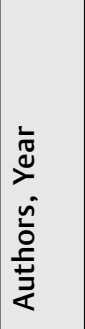 & 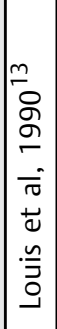 & 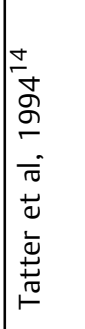 & 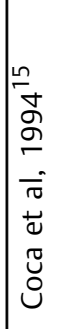 & 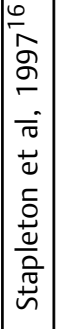 & 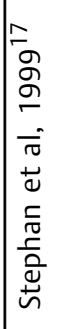 & 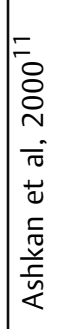 & 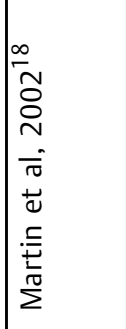 & 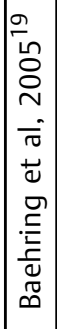 & 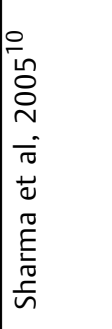 & 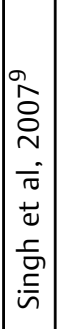 & 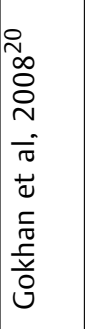 & 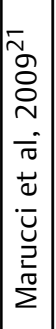 & 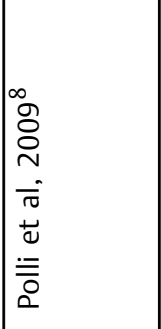 & 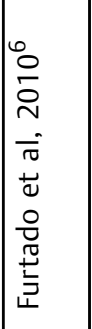 & 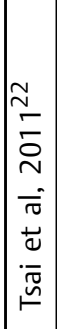 & 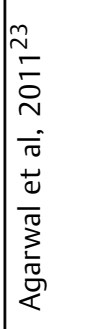 & 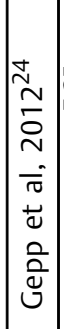 & 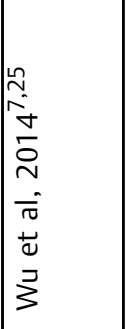 & 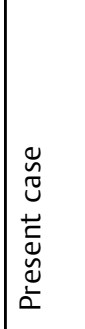 \\
\hline 10 & - & $N$ & $m$ & $\nabla$ & Ln & 6 & n & $\infty$ & $a$ & 은 & $=$ & $\simeq$ & $m$ & 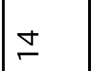 & $\stackrel{n}{-}$ & 6 & $\approx$ & $\stackrel{\infty}{-}$ & 9 \\
\hline
\end{tabular}


and are associated with a syrinx. Multimodal MRI has never been performed in SN. Metastasis has been reported in only one case ${ }^{10}$ : a recurrent cervical spine neurocytoma that was disseminated in the cerebellum 14 months later.

Histologically, neurocytomas are composed of monomorphic cells with round nuclei, grouped in clusters surrounded, in low cell-density areas, by a neuropil-like fibrillary matrix. GFAP is rarely detected, whereas EVNs show a strong immunopositivity for synaptophysin and S100. Epithelial membrane antigen (EMA), p53 protein, and chromogranin are negative. EVNs are characterized by a low mitotic index. "Atypical" EVNs have been also reported in the literature and are characterized by histologic atypia or anaplastic features, hemorrhage, and necrosis, but these findings do not correlate with malignant transformation. $^{10-12}$

The most frequent differential diagnoses include astrocytomas, ependymomas, oligodendrogliomas, meningiomas, neuroblastomas, and metastasis.

The treatment is based on a gross total or subtotal resection. Radiotherapy is considered beneficial for preventing tumor recurrence, particularly when total removal cannot be achieved.

The literature review suggests that this tumor has a generally favorable prognosis, essentially when a gross total resection is performed. The patient can expect significant and gradual recovery of motor strength and sensory capacities. However, recurrence would be more frequent in large residual tumor.

\section{Conclusion}

$\mathrm{SN}$ is a rare entity with only sporadic cases reported in the literature. As well as the central neurocytoma, it is characterized by a slow and benign course. Surgical resection is the gold standard treatment and diagnosis is made with immunohistochemical study. Recurrences are rare, and then radiotherapy may be undertaken.

\section{References}

1 Hassoun J, Gambarelli D, Grisoli F, et al. Central neurocytoma. An electron-microscopic study of two cases. Acta Neuropathol 1982;56(02):151-156

2 Brat DJ, Scheithauer BW, Eberhart CG, Burger PC. Extraventricular neurocytomas: pathologic features and clinical outcome. Am J Surg Pathol 2001;25(10):1252-1260

3 Giangaspero F, Cenacchi G, Losi L, Cerasoli S, Bisceglia M, Burger PC. Extraventricular neoplasms with neurocytoma features. A clinicopathological study of 11 cases. Am J Surg Pathol 1997; 21(02):206-212

4 Patil AS, Menon G, Easwer HV, Nair S. Extraventricular neurocytoma, a comprehensive review. Acta Neurochir (Wien) 2014;156(02):349-354

5 Ahmad Z, Din NU, Memon A, Tariq MU, Idrees R, Hasan S. Central, extraventricular and atypical neurocytomas: a clinicopathologic study of 35 cases from Pakistan plus a detailed review of the published literature. Asian Pac J Cancer Prev 2016;17(03): $1565-1570$

6 Furtado A, Arantes M, Silva R, Romao H, Resende M, Honavar M. Comprehensive review of extraventricular neurocytoma with report of two cases, and comparison with central neurocytoma. Clin Neuropathol 2010;29(03):134-140

7 Wu L, Deng X, Yang C, Zhao L, Yang T, Xu Y. Primary spinal neurocytoma involving the medulla oblongata: two case reports and a literature review. Neurol Med Chir (Tokyo) 2014;54(05): 417-422

8 Polli FM, Salvati M, Miscusi M, Delfini R, Giangaspero F. Neurocytoma of the spinal cord: report of three cases and review of the literature. Acta Neurochir (Wien) 2009;151(06): 569-574, discussion 574

9 Singh A, Chand K, Singh H, Sarkar C, Sharma MC. Atypical neurocytoma of the spinal cord in a young child. Childs Nerv Syst 2007;23(02):207-211

10 Sharma S, Sarkar C, Gaikwad S, Suri A, Sharma MC. Primary neurocytoma of the spinal cord: a case report and review of literature. J Neurooncol 2005;74(01):47-52

11 Ashkan K, Casey AT, D'Arrigo C, Harkness WF, Thomas DG. Benign central neurocytoma. Cancer 2000;89(05):1111-1120

12 Vasiljevic A, François P, Loundou A, et al. Prognostic factors in central neurocytomas: a multicenter study of 71 cases. Am J Surg Pathol 2012;36(02):220-227

13 Louis DN, Swearingen B, Linggood RM, et al. Central nervous system neurocytoma and neuroblastoma in adults-report of eight cases. J Neurooncol 1990;9(03):231-238

14 Tatter SB, Borges LF, Louis DN. Central neurocytomas of the cervical spinal cord. Report of two cases. J Neurosurg 1994;81(02):288-293

15 Coca S, Moreno M, Martos JA, Rodriguez J, Barcena A, Vaquero J. Neurocytoma of spinal cord. Acta Neuropathol 1994;87(05): 537-540

16 Stapleton SR, David KM, Harkness WF, Harding BN. Central neurocytoma of the cervical spinal cord. J Neurol Neurosurg Psychiatry 1997;63(01):119

17 Stephan CL, Kepes JJ, Arnold P, Green KD, Chamberlin F. Neurocytoma of the cauda equina. Case report. J Neurosurg 1999;90(2, Suppl):247-251

18 Martin AJ, Sharr MM, Teddy PJ, Gardner BP, Robinson SF. Neurocytoma of the thoracic spinal cord. Acta Neurochir (Wien) 2002;144(08):823-828

19 Baehring J, Ogle E, Sze G, Duncan C, Bannykh S. Ganglioneurocytoma of the spinal cord. J Neurooncol 2005;71(02):149

20 Gokhan GA, Gurer IE, Akyuz M, Tuncer R. A case of extraventricular neurocytoma of the spinal cord. Neuropathology 2008; 28(03):322-325

21 Marucci G, Barbanera A, Serchi E, Andreoli A. Ganglioneurocytoma of the spinal cord: report of a case and review of literature. Eur Spine J 2009;18(Suppl 2):183-185

22 Tsai CY, Tsai TH, Lin CH, Cheng YH, Lieu AS. Unusual exophytic neurocytoma of thoracic spine mimicking meningioma: a case report and review of the literature. Eur Spine J 2011;20(Suppl 2): S239-S242

23 Agarwal S, Sharma MC, Sarkar C, et al. Extraventricular neurocytomas: a morphological and histogenetic consideration. A study of six cases. Pathology 2011;43(04):327-334

24 Gepp Rde A, Sacco RC, Brandão ICS, Braga da Silveira E, Monteiro Júnior A. Central neurocytoma of spinal cord. Arq Neuropsiquiatr 2012;70(03):234-235

25 Sun Z, Yuan D, Cui Z, et al. Intramedullary neurocytomas in the craniocervical spinal cord: a report of two cases and a literature review. Oncol Lett 2015;9(01):86-90 